\title{
Earthquake-Induced Collapse Risk and Loss Assessment of Steel Concentrically Braced Frames
}

\author{
Seong-Hoon Hwang ${ }^{1, \text { a }}$ and Dimitrios G. Lignos ${ }^{2, b^{*}}$ \\ ${ }^{1} \mathrm{Ph}$.D. student, Swiss Federal Institute of Technology, Lausanne (EPFL), Switzerland \\ ${ }^{2}$ Associate Professor, Swiss Federal Institute of Technology, Lausanne (EPFL), Switzerland \\ aseong-hoon.hwang@epfl.ch, bdimitrios.lignos@epfl.ch
}

\begin{abstract}
Keywords: Earthquake loss assessment; Collapse risk; Special concentrically braced frames; Gravity framing; Residual deformations.
\end{abstract}

\begin{abstract}
This paper quantifies the collapse risk and earthquake-induced losses for a wide range of archetype buildings with special concentrically braced frames (SCBFs). The collapse risk and expected economic losses associated with repair, demolition and collapse are computed based on a performance-based earthquake engineering framework developed within the Pacific Earthquake Engineering Research Center. It is shown that the collapse risk of the steel SCBF archetypes may be significantly overestimated when the influence of the gravity framing system on the lateral frame strength and stiffness is ignored. It is also found that the building-specific earthquake loss assessment is significantly overestimated at low probability of occurrence seismic events (i.e., $2 \%$ probability of occurrence in 50 years) when the gravity framing system is not modeled explicitly as part of the nonlinear building model. For frequent and design-basis seismic events (i.e., 50 and 10\% probability of exceedance over 50 years of building life expectancy), acceleration-sensitive nonstructural component repairs govern the building losses regardless of the employed nonlinear building model representation. For the same seismic events, steel brace flexural buckling contributes to structural repair losses.
\end{abstract}

\section{Introduction}

Steel concentrically braced frames (CBFs) are a commonly used as lateral load-resisting system in highly seismic regions. These systems are likely to develop local story mechanisms due to the drift concentrations within certain story(ies) of the CBF. Such a mechanism may result in large residual drifts and structural collapse $[1,2]$. Steel CBFs is likely to experience high absolute floor acceleration demands even at low seismic intensities due to their high lateral stiffness [3,4]. Moreover, prior studies $[5,6]$ indicated that steel brace flexural buckling is typically triggered at relatively small story drifts. Therefore, earthquake-induced losses in steel CBFs may be induced due to steel brace damage and acceleration-sensitive nonstructural components at low to moderate seismic intensities.

The next generation of the performance-based earthquake engineering (PBEE) framework [7] allows for the computation of building-specific expected losses in a rational manner. However, despite of the beneficial influence of the gravity framing on the story drift demand distribution and the reserve capacity of a building [8-10], there has not been an attempt to quantify such effects on building-specific losses in the aftermath of an earthquake. A number of studies quantified earthquakeinduced losses mainly for conventional reinforced concrete [11-13] and wood structures [14-16]. To the best of the authors' knowledge, prior studies have not quantified the expected structural/nonstructural repairs in steel frame buildings with CBFs subjected to earthquake shaking.

This paper discusses a numerical study that quantifies the earthquake-induced losses in archetype steel frame buildings designed with perimeter special concentrically braced frames (SCBFs) based on today's seismic design provisions in North America. The emphasis is placed on the effect of the interior gravity framing system on the aforementioned aspects. Residual deformations are explicitly considered such that the likelihood of building demolition is explicitly quantified. 


\section{Overview of Employed Loss Estimation Methodology}

The damage-loss modeling is conducted based on the building-specific loss methodology proposed by Ramirez and Miranda [13]. The methodology can account for all possible losses: (i) due to structural/nonstructural component repairs, conditioned on no building collapse; (ii) due to building demolition, conditioned on no building collapse; and (iii) due to building collapse. By assuming collectively exhaustive events of possible losses, the expected losses in a building conditioned on a seismic intensity measure $(I M)$ (i.e., $\left.E\left[L_{T} \mid I M\right]\right)$ can be defined as follows:

$$
E\left[L_{T} \mid I M\right]=E\left[L_{R} \mid N D, N C, I M\right]+E\left[L_{D} \mid N C, I M\right]+E\left[L_{C} \mid C, I M\right]
$$

in which, $E\left[L_{R} \mid N D, N C, I M\right]=$ expected losses due to structural/nonstructural component repairs conditioned on no building collapse and no building demolition, and on an $I M ; E\left[L_{D} \mid N C, I M\right]=$ expected loss due to building demolition conditioned on the building not collapsing and on the seismic intensity $I M$; and $E\left[L_{C} \mid C, I M\right]=$ collapse loss conditioned on the $I M$. By assuming that three outcomes are mutually exclusive, Eq. (1) can be rewritten as:

$$
\begin{aligned}
E\left[L_{T} \mid I M\right] & =E\left[L_{R} \mid R, I M\right](1-P[D \mid I M])(1-P[C \mid I M]) \\
& +E\left[L_{D} \mid D\right] P[D \mid I M](1-P[C \mid I M])+E\left[L_{C} \mid C\right] P[C \mid I M]
\end{aligned}
$$

in which, $E\left[L_{R} \mid R, I M\right]=$ expected losses due to structural/nonstructural component repairs given a seismic intensity $I M ; E\left[L_{D} \mid D\right]$ and $E\left[L_{C} \mid C\right]=$ expected losses in the building when the building may be demolished and when the building collapse occurs, respectively; $P[D \mid I M]=$ probability that the building may be demolished conditioned on the seismic $I M$; and $P[C \mid I M]$ = probability of collapse given the seismic intensity $I M$. The probability of demolition given an $I M, P[D \mid I M]$ in Eq. (2) can be determined as follows:

$$
P[D \mid I M]=\int_{0}^{\infty} P[D \mid R S D R] p(R S D R \mid I M) \mathrm{d} R S D R
$$

in which, $P[D \mid R S D R]=$ probability of having to demolish a building conditioned on the maximum residual story drift ratio (RSDR) along the building height, which is defined by a lognormal distribution with a median of 0.015 radians and a logarithmic standard deviation of 0.3 [13]; and $p(R S D R \mid I M)=$ probability density function of the maximum residual drift ratio along the height of the building, given an $I M$ level.

Another loss-metric employed in this paper is the expected annual loss $(E A L)$. The $E A L$ is computed by integrating the expected economic losses over the entire range of a seismic hazard curve at the design site as follows:

$$
E A L=\int_{0}^{\infty} E\left[L_{T} \mid I M\right] \cdot\left|\frac{\mathrm{d} \lambda_{I M}}{\mathrm{~d} I M}\right| \mathrm{d} I M
$$

in which, $\lambda_{I M}$ is the mean annual frequency of the seismic intensity $I M$ at the site of interest.

\section{Description of Steel Frame Buildings with perimeter SCBFs}

Four archetypes ranging from 2 to 12 stories are considered in the present study. The archetypes are assumed to be standard office buildings designed per ASCE/SEI 7-05 [17] and ANSI/AISC 341-05 [18]. The archetypes are located on a site with stiff soil with an average shear wave velocity $v_{s}=285$ $\mathrm{m} / \mathrm{s}$. To investigate the influence of key seismic design parameters on the expected losses in steel frame buildings with SCBFs, two sets of archetypes in which the employed seismic design category (SDC) varies. The first set is located in Sacramento at $38.579^{\circ} \mathrm{N}, 121.493^{\circ} \mathrm{W}$, assigned to the lower- 
bound of SDC $D$ (i.e., denoted as $D_{\min }$ ). The second one is located in the downtown area of Los Angeles at $33.996^{\circ} \mathrm{N}, 118.162^{\circ} \mathrm{W}$, assigned to the upper-bound of SDC $D$ (i.e., denoted as $D_{\max }$ ), as given in ASCE/SEI 7-05 [17].

Shown in Fig. 1 are the floor plan and elevation view of the 6-story archetype designed for SDC $D_{\max }$. A two-story X-brace configuration is adopted to avoid large unbalanced forces once steel braces buckle [see Fig. 1(b)]. Details about archetype building design can be found in [19].

Figure 2 illustrates the design spectrum and hazard curves for the steel frame buildings under consideration. The design spectrum constructed for SDC $D_{\max }$ and $D_{\min }$ based on ASCE/SEI 7-05 [17]. The seismic hazard curve data for the two design locations are obtained from the United States Geological Survey (USGS) website.

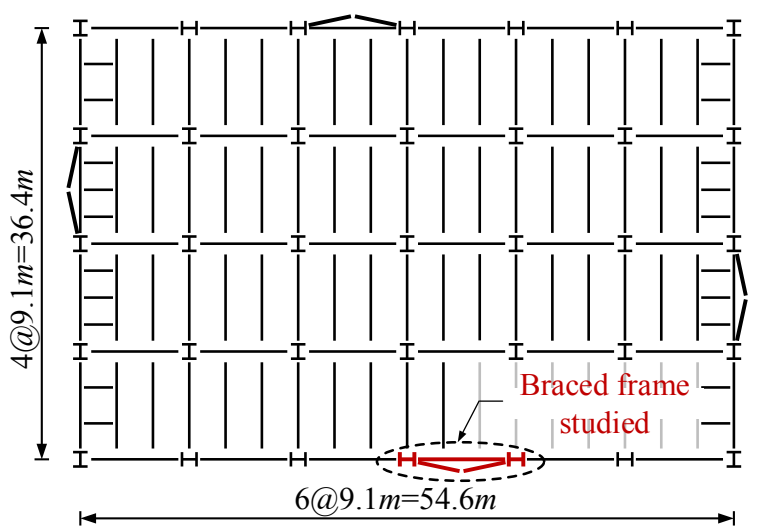

(a)

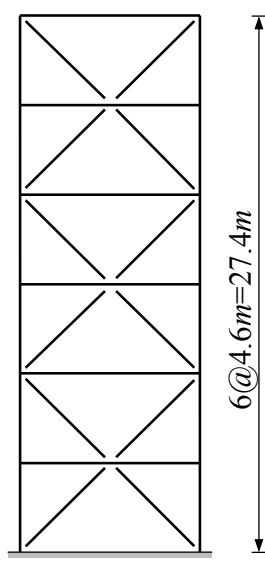

(b)

Figure 1. 6-story archetype building with perimeter SCBFs: (a) typical plan view; and (b) elevation view.

The replacement costs of the archetype buildings are estimated to be a unit cost of $\$ 1,880$ per square meter in 2013 US dollars based on the RS Means Cost Estimating Manuals [20]. The architectural layout is assumed to be a rectangular floor area of $2006.71 \mathrm{~m}^{2}$ as shown in Fig. 1(a). The fragility curves of the various damageable components including the repair costs for various damage states are discussed in detail in $[21,22]$.

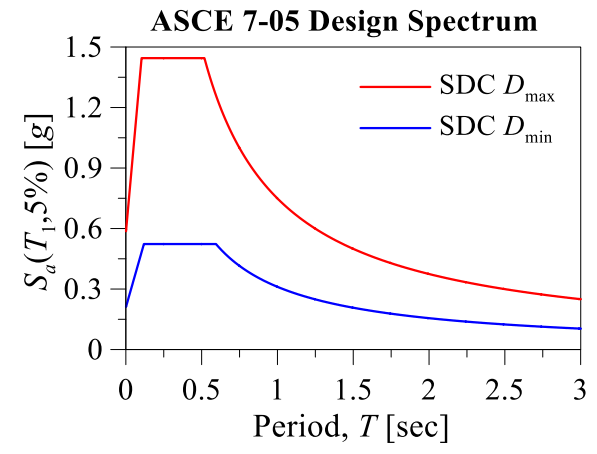

(a)

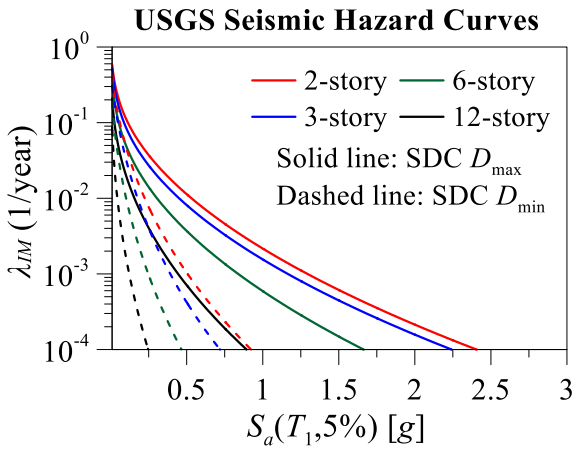

(b)

Figure 2. Design spectrum and site-specific seismic hazard curves for bare model representations of archetype buildings with SCBFs: (a) design spectrum; (b) site-specific seismic hazard curves.

\section{Nonlinear Building Models and Collapse Simulations}

The archetype buildings are modeled as 2-dimensional (2-D) using the Open System for Earthquake Engineering Simulation (OPENSEES) platform [23]. To evaluate the effect of the gravity framing system on the loss estimation, two different numerical models of the archetypes are considered: (i) a model that represents only bare steel SCBFs (noted as $B$ model); and (ii) a model that considers the effects of the composite slab and the gravity framing system on the lateral strength and stiffness of the steel frame building (noted as $C G$ model), as proposed in [8]. The steel braces are modeled with 
displacement-based beam-column elements that simulate flexural buckling and fracture initiation due to low-cycle fatigue according to the modeling recommendations by Karamanci and Lignos [24]. The inelastic behavior of steel SCBF beams and columns is modeled with a lumped-plasticity deterioration model $[25,26]$. The P-Delta effects are explicitly captured through the corotational transformation. To conduct nonlinear response history analysis for each numerical model, a set of 44 far-field ground motions obtained from FEMA P695 [27]. Incremental dynamic analysis [28] is carried out to simulate the entire range of engineering demand parameters of interest.

\section{Earthquake-induced Collapse Risk}

To facilitate the earthquake-induced collapse risk and loss assessment, the collapse fragility curves are computed for the numerical models that describe the probability of collapse, $P[C \mid I M]$ given the first mode spectral acceleration, $S_{a}\left(T_{1}, 5 \%\right)$ of the respective archetype based on IDA results. A mean annual frequency of collapse, $\lambda_{c}$ is employed to interpret the collapse risk by integrating the collapse fragility curve of the respective model over the associated hazard curve [29] as follows:

$$
\lambda_{c}=\int_{0}^{\infty} P[C \mid I M] \cdot\left|\frac{\mathrm{d} \lambda_{I M}}{\mathrm{~d} I M}\right| \mathrm{d} I M
$$

in which, $\mathrm{d} \lambda_{I M} / \mathrm{d} I M$ is the slope of the site-specific hazard curve at the design site. By assuming a Poisson distribution [30], the probability of collapse within $t$ years of a building's life expectancy for a given $\lambda_{\mathrm{c}}$ can be determined as $P_{c}$ (in $t$ years $)=1-e^{-\lambda_{c} t}$.

Figure 3 illustrates the collapse probability over 50 years of the building life expectancy, $P_{c}$ (in 50 years) of the numerical models for the archetype buildings designed for SDC $D_{\max }$ and $D_{\min }$. From these figures, the collapse risk of the archetypes computed based on the $C G$ models is decreased by a factor of 2.3, on average, relative to that computed based on $B$ models. This is mainly due to the beneficial effect of the gravity framing system on the mitigation of story drift concentrations $[8,10]$. In the case of $C G$ models, a $1 \%$ probability of collapse within 50 years specified in ASCE/SEI 7-10 [31] is also achieved. However, when a $B$ model is utilized, such limit is not met in most cases. The only exception is the 3 -story archetype designed for SDC $D_{\max }$. In that respect, the collapse risk of steel frame buildings with SCBFs located in highly seismic regions (i.e., SDC $D_{\max }$ ) can be significantly overestimated when ignoring the gravity framing system from the numerical model.

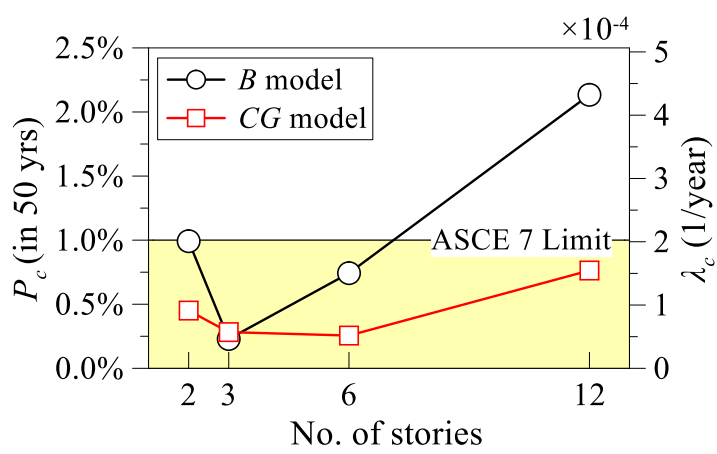

(a) $\operatorname{SDC} D_{\max }$

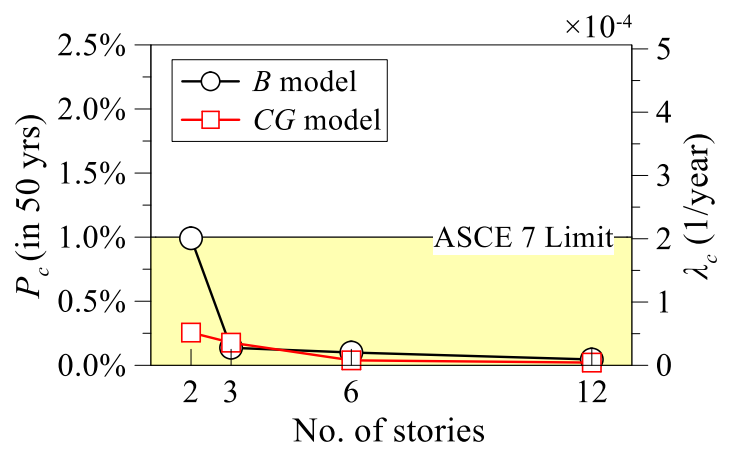

(b) $\operatorname{SDC} D_{\min }$

Figure 3. Mean annual frequency of collapse, $\lambda_{c}$ and the corresponding collapse probability within 50 years,

$P_{\mathrm{c}}$ (in 50 years) for archetype buildings with perimeter SCBFs: (a) SDC $D_{\max }$; and (b) SDC $D_{\min }$.

\section{Expected Losses Conditioned on Seismic Intensity}

Shown in Fig. 4 are the loss vulnerability curves for the 6-story archetype buildings computed based on the $B$ models. Such curves illustrate the building-specific expected losses as a function of the seismic intensity $I M, S_{a}\left(T_{1}, 5 \%\right)$. The expected losses are normalized with respect to the corresponding building's replacement cost. The expected losses given an $I M$ are further disaggregated into losses due to structural/nonstructural component repairs, losses due to demolition, and losses due to 
structural collapse. Additional horizontal axes are placed at the top of Fig. 5, which represent the IM normalized with respect to the spectral acceleration associated with a design-basis earthquake (DBE) as per ASCE/SEI 7-05 [17].

Referring to Fig. (4), losses due to nonstructural component repairs primarily dominate the expected losses up to the DBE intensity regardless of the seismic design category. For the 6-story archetype building designed for SDC $D_{\max }$ [see Fig. 4(a)], the demolition loss due to excessive residual drifts is a primary contributor to the expected losses at seismic intensities associated with $1.5 \times$ DBE [i.e., a maximum considered earthquake (MCE)]. Same findings hold true for other midand high-rise steel SCBF frames considered in this study [22]. For the 6-story archetype designed for SDC $D_{\text {min, }}$ losses due to demolition as well as collapse are negligible even at the MCE level. This is because of the low collapse risk of the building as shown earlier in Fig. 3(b).

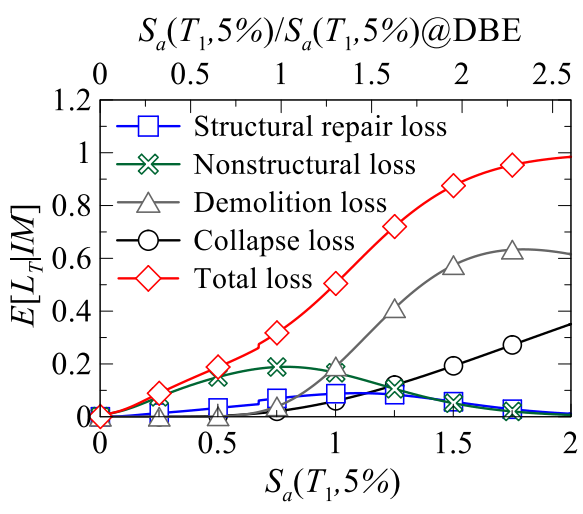

(a) 6-story SCBFs for SDC $D_{\text {max }}$

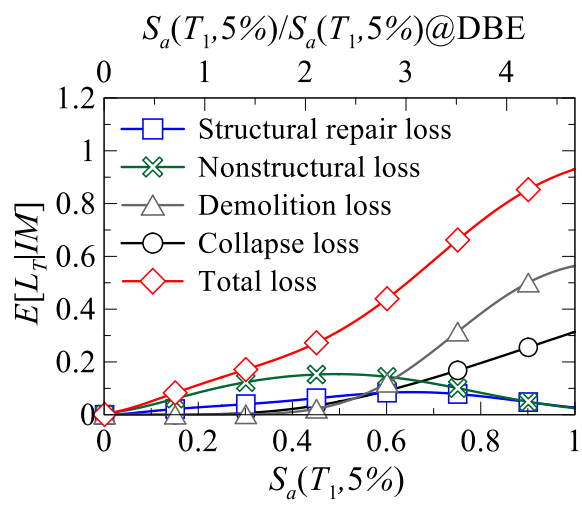

(b) 6-story SCBFs for SDC $D_{\min }$

Figure 4. Normalized loss vulnerability curves for 6-story steel frame buildings with perimeter SCBFs as a function of the seismic intensity IM: (a) SDC $D_{\max }$; and (b) SDC $D_{\min }$.

Figure 5 illustrates the expected losses for selected archetypes as computed based on $B$ and $C G$ models at selected seismic intensities [i.e., service-level earthquake (SLE), DBE and MCE]. At low to moderate seismic intensities (i.e., SLE and DBE), expected losses are mainly governed by acceleration-sensitive nonstructural component repairs regardless of the number of stories and the seismic design category. At DBE, losses due to structural component repairs are considerable. This is due to steel brace flexural buckling. At MCE, economic losses of the archetype buildings designed for a SDC $D_{\max }$ are largely governed by building demolition. However, the employed nonlinear building model representation is very critical in this case. In particular, unless if a $C G$ model is employed the expected losses due to building demolition are largely overestimated. This does not seem to be an issue for archetypes designed for SDC $D_{\min }$ as shown in Fig. 5(b). Therefore, the earthquake-induced loss assessment can be adequately computed based on $C G$ model representations.

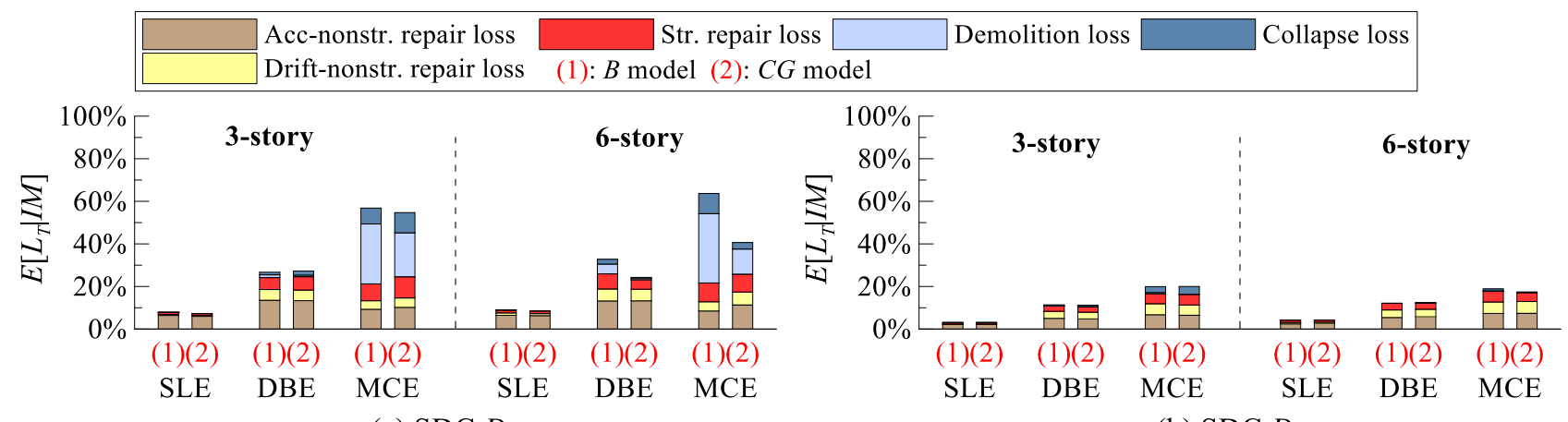

(a) $\operatorname{SDC} D_{\max }$

(b) $\operatorname{SDC} D_{\min }$

Figure 5. Normalized expected losses of 3- and 6-story steel frame buildings with perimeter SCBFs at selected seismic intensities: (a) SDC $D_{\max }$; and (b) SDC $D_{\min }$. 


\section{Expected Annual Losses and Present Values}

Figure 6 illustrates the normalized EALs and corresponding present value (PV) of lifecycle costs for all the archetype buildings with perimeter SCBFs designed for SDC $D_{\max }$ and $D_{\min }$. The PV is computed simply by multiplying a building's $E A L$ by its expected remaining life $T$ with a discount rate $r\left(=\sum_{i=1}^{T}(1+r)^{-i}\right)$. A discount rate of $3 \%$ is considered in this paper. A remaining building's life, $T$ of 50 years is assumed. The values shown in Fig. 6 are normalized with respect to the total replacement cost of the respective building. From this figure, the $E A L$ values of the archetype buildings range from 0.74 to $0.87 \%$ for SDC $D_{\max }$ and from 0.39 to $0.65 \%$ for SDC $D_{\min }$. Note that in this case the effect of the numerical model choice on the EALs is insignificant. These values are slightly larger but consistent with EALs of steel frame buildings with moment-resisting frames [32]. It is also evident that losses due to acceleration-sensitive nonstructural component repair primarily governs the EALs regardless of the numerical model choice and the seismic design category. These are attributed to the following reasons: (i) high absolute floor acceleration demands along the building height are expected because SCBFs are inherently stiff lateral load resisting systems; and (ii) the $E A L$ is largely influenced by frequently occurring earthquakes rather than seismic events with a low probability of occurrence $[22,29]$. Referring to Fig. 6, the contribution of structural component repairs to the EALs is considerable. This is due to the early onset of steel brace flexural buckling (i.e., $0.5 \%$ story drifts on average), that is typically caused by frequently and moderately frequent seismic events. Hwang and Lignos [22] have found that such loss contributions can be quantified in a more reliable manner if bivariate fragility curves are considered within the earthquake-induced loss assessment. Such fragility curves [5] consider the influence of the geometric properties of the respective steel brace to compute the probability of being of exceeding a certain damage state.

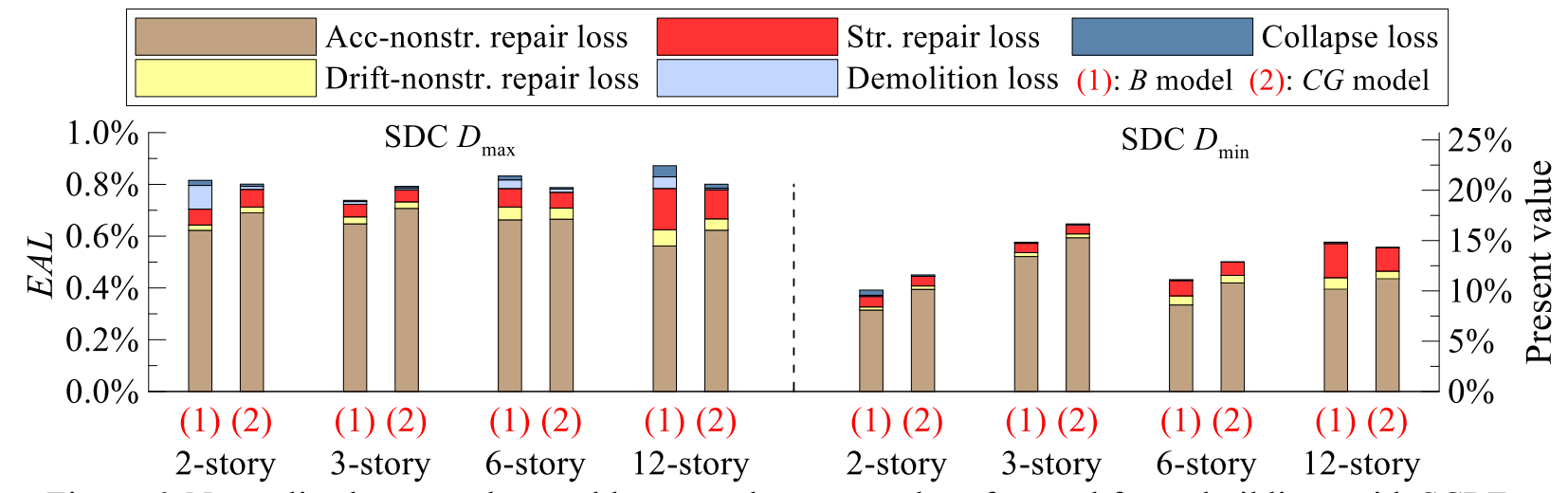

Figure 6. Normalized expected annual losses and present values for steel frame buildings with SCBFs.

\section{Conclusions}

This paper assesses the collapse risk and earthquake-induced losses of steel frame buildings with perimeter special concentrically braced frames (SCBFs). The main findings are summarized as follows:

- The collapse risk of steel frame buildings with SCBFs is largely overestimated when ignoring the gravity framing in the numerical model representation of the respective building.

- At low to moderate seismic intensities, damage to the nonstructural components of steel frame buildings with SCBFs is the major contributor to buildings' losses regardless of the numerical model choice of the respective building.

- At seismic intensities associated with frequent and design-basis earthquakes, appreciable losses due to structural component repairs are observed. This is due to steel brace flexural buckling at relatively small drifts.

- When losses are evaluated at a given seismic intensity, it is advisable that the composite slab and the gravity framing system should be explicitly considered in the numerical model representation of the respective building of interest. Otherwise, losses due to demolition and structural collapse 
would be overestimated by a factor of two. This is not the case for buildings designed in relative moderate seismic regions (i.e., seismic design category $D_{\min }$ ).

- The effect of the nonlinear building model choice is not significant on the expected annual loss computations.

\section{References}

[1] R. Tremblay, A. Filiatrault, M. Bruneau, M. Nakashima, H.G.L. Prion, R. DeVall, Seismic design of steel buildings: lessons from the 1995 Hyogo-ken Nanbu earthquake. Canadian Journal of Civil Engineering, 23(3): 727-756, 1996.

[2] R. Tremblay, A. Filiatrault, P. Timler, M. Bruneau, Performance of steel structures during the 1994 Northridge earthquake. Canadian Journal of Civil Engineering, 22(2): 338-360, 1995.

[3] S. Ray-Chaudhuri, T.C. Hutchinson, Effect of nonlinearity of frame buildings on peak horizontal floor acceleration. Journal of Earthquake Engineering, 15(1): 124-142, 2011.

[4] M.E. Rodriguez, J.I. Restrepo, A.J. Carr, Earthquake-induced floor horizontal accelerations in buildings. Earthquake Engineering \& Structural Dynamics, 31(3): 693-718, 2002.

[5] D.G. Lignos, E. Karamanci, Drift-based and dual-parameter fragility curves for concentrically braced frames in seismic regions. Journal of Constructional Steel Research, 90(0): 209-220, 2013.

[6] C.W. Roeder, E.J. Lumpkin, D.E. Lehman, Seismic performance assessment of concentrically braced steel frames. Earthquake Spectra, 28(2): 709-727, 2012.

[7] FEMA, Seismic performance assessment of buildings, volume 1 - methodology. Report No. FEMA P-58-1, Federal Emergency Management Agency, Washington, DC, 2012.

[8] A. Elkady, D.G. Lignos, Effect of gravity framing on the overstrength and collapse capacity of steel frame buildings with perimeter special moment frames. Earthquake Engineering \& Structural Dynamics, 44(8): 1289-1307, 2015.

[9] L.A. Fahnestock, E.M. Hines, R. Tremblay, C. Bradley, J. Nelson, T. Beland, A. Davaran, J. Sizemore. Reserve capacity and implications for seismic collapse prevention for low-ductility braced frames in moderate seismic regions. Proceedings of the 10th US National Conference on Earthquake Engineering: Frontiers of Earthquake Engineering, Anchorage, AK, (2014).

[10] X. Ji, M. Kato, T. Wang, T. Hitaka, M. Nakashima, Effect of gravity columns on mitigation of drift concentration for braced frames. Journal of Constructional Steel Research, 65(12): 2148-2156, 2009.

[11] M. Baradaran Shoraka, T.Y. Yang, K.J. Elwood, Seismic loss estimation of non-ductile reinforced concrete buildings. Earthquake Engineering \& Structural Dynamics, 42(2): 297-310, 2013.

[12] C.M. Ramirez, A.B. Liel, J. Mitrani-Reiser, C.B. Haselton, A.D. Spear, J. Steiner, G.G. Deierlein, E. Miranda, Expected earthquake damage and repair costs in reinforced concrete frame buildings. Earthquake Engineering \& Structural Dynamics, 41(11): 1455-1475, 2012.

[13] C.M. Ramirez, E. Miranda, Significance of residual drifts in building earthquake loss estimation. Earthquake Engineering \& Structural Dynamics, 41(11): 1477-1493, 2012.

[14] M. Koliou, J.W. van de Lindt, A. Filiatrault, Evaluation of an alternative seismic design approach for rigid wall flexible wood roof diaphragm buildings through probabilistic loss estimation and disaggregation. Engineering Structures, 127:31-39, 2016.

[15] S. Pei, J.W. van de Lindt, Methodology for earthquake-induced loss estimation: An application to woodframe buildings. Structural Safety, 31(1): 31-42, 2009.

[16] K.A. Porter, C.R. Scawthorn, J.L. Beck, Cost-effectiveness of stronger woodframe buildings. Earthquake Spectra, 22(1): 239-266, 2006. 
[17] ASCE. Minimum design loads for buildings and other structures, ASCE/SEI 7-10. American Society of Civil Engineers: Reston, VA, 2006.

[18] AISC. Seismic provisions for structural steel buildings, ANSI/AISC 341-05. American Institute of Steel Construction: Chicago, IL, 2005.

[19] NIST, Evaluation of the FEMA P-695 methodology for quantification of building seismic performance factors. NIST GCR 10-917-8, NEHRP Consultants Joint Venture, Gaithersburg, MD, 2010.

[20] RS Means. RS Means Square Foot Costs, RS Means Corporation: Kingston, MA. USA., 2013.

[21] S.-H. Hwang, A. Elkady, S. Al.Bardaweel, D.G. Lignos, Earthquake loss assessment of steel frame buildings designed in highly seismic regions. Proceedings of the 5th ECCOMAS Thematic Conference on Computational Methods in Structural Dynamics and Earthquake Engineering, Crete Island, Greece, (2015).

[22] S.-H. Hwang, D.G. Lignos, Effect of modeling assumptions on the earthquake-induced losses and collapse risk of steel-frame buildings with special concentrically braced frames. Journal of Structural Engineering, 143(9): 04017116, 2017.

[23] F.T. Mckenna, Object-oriented finite element programming: frameworks for analysis, algorithms and parallel computing. Ph.D. Thesis, Department of Civil Engineering, University of California, Berkeley, CA, 1997.

[24] E. Karamanci, D.G. Lignos, Computational approach for collapse assessment of concentrically braced frames in seismic regions. Journal of Structural Engineering, 140(8): A4014019, 2014.

[25] L.F. Ibarra, R.A. Medina, H. Krawinkler, Hysteretic models that incorporate strength and stiffness deterioration. Earthquake Engineering and Structural Dynamics, 34(12): 1489-1511, 2005.

[26] D.G. Lignos, H. Krawinkler, Deterioration modeling of steel components in support of collapse prediction of steel moment frames under earthquake loading. Journal of Structural Engineering, 137(11): 1291-1302, 2011.

[27] FEMA, Quantification of building seismic performance factors. Report No. FEMA-P695, Federal Emergency Management Agency (FEMA), Washington, DC, 2009.

[28] D. Vamvatsikos, C.A. Cornell, Incremental dynamic analysis. Earthquake Engineering and Structural Dynamics, 31(3): 491-514, 2002.

[29] L. Eads, E. Miranda, H. Krawinkler H., D. G. Lignos, An efficient method for estimating the collapse risk of structures in seismic regions. Earthquake Engineering \& Structural Dynamics, 42(1): 25-41, 2013.

[30] C.A. Cornell, Engineering seismic risk analysis. Bulletin of the Seismological Society of America, 58(5): 1583-1606, 1968.

[31] ASCE. Minimum design loads for buildings and other structures, ASCE/SEI 7-10. American Society of Civil Engineers (ASCE): Reston, VA, 2010.

[32] S.-H. Hwang, D.G. Lignos, Earthquake-induced loss assessment of steel frame buildings with special moment frames designed in highly seismic regions. Earthquake Engineering \& Structural Dynamics: 46(13): 2141-2162, 2017. 